\title{
Трансформация рыночной среды промышленных предприятий как результат проявления эффектов импортозамещения
}

\author{
Старикова М.С., Дубровина Т.А. \\ Белгородский государственный технологический университет им. В.Г. Шухова, \\ Россия, 308012, г. Белгород, ул. Костюкова 46 \\ E-mail: s_ms@bk.ru, t.kos92@mail.ru
}

\begin{abstract}
Аннотация
В статье представлены результаты реализации политики импортозамещения в Российской Федерации. Проанализированы дефиниции, где отразилась суть понятия импортозамещения, а также предложен авторский подход к определению импортозамещения и выделены ключевые концепции импортозамещения. В результате анализа товарной структуры импорта Российской Федерации сделан вывод о наибольшей эффективности мер политики импортозамещения в продовольственном секторе, что подтверждается данными о приросте внутреннего производства в большинстве его подотраслей. На основе оценки кейса мясной промышленности, как демонстрирующей наибольший вклад в эффект импортозамещения в продовольственном секторе, выделены тенденции изменения структуры спроса, насыщения рынка и укрупнения бизнеса, что препятствует формированию национальной экономики предпринимательского типа, движимой малым бизнесом, в том числе в промышленности.
\end{abstract}

Ключевые слова: политика импортозамещения, эффекты импортозамещения, современная рыночная среда, маркетинг импортозамещения.

Благодарности: статья подготовлена по НИР в рамках мероприятий Программы развития опорного университета на базе БГТУ им. В.Г. Шухова до 2021 года «Маркетинг управления конкурентоспособностью предприятий в условиях цифровой экономики» № A-27/20 от 15 января 2020 года.

Для цитирования: Старикова М.С., Дубровина Т.А. 2020. Трансформация рыночной среды промышленных предприятий как результат проявления эффектов импортозамещения. Экономика. Информатика. 47 (4): 771-782. DOI 10.18413/2687-0932-2020-47-4-771-782.

\section{Transformation of the market environment of industrial enterprises as a result of import substitution effects}

\author{
Starikova M.S., Dubrovina T.A. \\ BSTU after V.G. Shukhov., 46 Kostyukova St, Belgorod, 308012, Russia \\ E-mail: s_ms@bk.ru, t.kos92@mail.ru
}

\begin{abstract}
The article presents the results of the implementation of the import substitution policy in the Russian Federation. As a result of the analysis of definitions, the authors formulated the essence of the concept of import substitution and the author's approach to the definition of import substitution, highlighting the key concepts of import substitution. The analysis of the commodity structure of imports of the Russian Federation showed the greatest efficiency of import substitution policy measures in the food sector, which is confirmed by data on the growth of domestic production in most of its subsectors. The article assesses the case of the meat industry as demonstrating the greatest contribution to the effect of import substitution in the food sector. The tendencies of changes in the structure of demand, market saturation and business consolidation are highlighted, which prevents the formation of a national entrepreneurial economy driven by small businesses, including in industry.
\end{abstract}

Keywords: import substitution policy, import substitution effect, modern market environment, marketing of import substitution. 
Acknowledgements: the article was prepared on the basis of research and development in the framework of the activities of the Development Program of the flagship university on the basis of BSTU named after V.G. Shukhov until 2021 "Marketing of enterprise competitiveness management in the digital economy" No. A-27/20 dated January 15, 2020.

For citation: Starikova M.S., Dubrovina T.A. 2020. Transformation of the market environment of industrial enterprises as a result of import substitution effects. 47 (4): 771-782 (in Russian). DOI 10.18413/2687-09322020-47-4-771-782.

\section{Введение}

В статье предлагается проанализировать изменение рыночных условий функционирования промышленных предприятий, обусловленное реализацией политики импортозамещения. Значимость учета тенденций развития рынка обусловлена тем, что трансформация мезосреды предприятия влечет за собой качественное изменение инструментов маркетинга в части свойств продукта, способов его распространения, цены, программы продвижения, то есть всего набора компонентов конкурентоспособности. Иными словами, аудит преобразований рыночной среды является исходным этапом реализации маркетинга импортозамещения, понимаемого нами как управление рыночной деятельностью, с учетом изменений структуры рынка и конкурентной составляющей в процессе реализации политики импортозамещения. Целью данного исследования является изучение влияния реализации политики импортозамещения в приоритетных секторах экономики на рыночную ситуацию в стране, а также определение качественных конъюнктурных изменений, стоящих за количественными эффектами.

\section{Объекты и методы исследования}

Исследование базируется на структурно-динамическом измерении различных секторов народного хозяйства до и после реализации политики импортозамещения (РПИ) с различной степенью детализации анализа, обусловленной тенденциями развития секторов промышленности. В статье для периода «до» берутся данные за 2015 г., так как программа импортозамещения РФ введена в 2015 году, и «после» - данные за 2020 г. как результат РПИ.

\section{Результаты и их обсуждение}

Исходя из поставленных целей нами была изучена рыночная среда предприятия при реализации государственной политики импортозамещения, которая трансформируется, поскольку создаются дополнительные возможности увеличения рыночной доли на внутреннем рынке и укрепления экспортного потенциала при ориентации на внешние рынки. В России особое внимание проблемам импортозамещения стали уделять с 2014 года, когда изменились приоритеты международного сотрудничества. Спецификой проводимой политики является ее реактивный, а не упреждающий характер. В этом случае причинами реализации мер по замене импорта послужило введение санкций, а также необходимость поддержки обеспечения безопасности национальной экономики, недоброкачественная импортная продукция [Fanzo J., 2015, Schetinina E.D., 2018, Smyth S, 2015]. Условием же, сводящим к нулю результативность импортозамещения, является общая деградация промышленного производства. В этом смысле эффекты импортозамещения не всегда однозначны. Например, опыт реализации политики импортозамещения в странах Латинской Америки демонстрирует наличие отрицательных эффектов, а именно:

1) снижение выпуска продукции и замедление роста производства;

2) появление риска деградации производства;

3) спад экономики на мировом уровне. 
Но не только эти страны имеют опыт реализации политики импортозамещения, Белоруссия, Тайвань, США, Япония, Китай, Бразилия и др. также имеют опыт в РПИ.

В результате анализа представленных в таблице 1 определений, а также позиций некоторых других авторов [Ван дер Вее, 1994, Волкодавов, 2009, Гулин, 2015, Зайцев, 2002, Исмагилова, 2004, Лукьянчук, 2011, Макаров, 2011, Назарчук, 2007] можно выделить такие ключевые концепции импортозамещения, как:

1. Импортозамещение как политика повышения качества и конкурентоспособности отечественной продукции.

2. Импортозамещение как путь к достижению экономической независимости за счет замены импортной продукции отечественной.

3. Импортозамещение как способ выйти на мировой уровень и настроить мирохозяйственные связи.

4. Импортозамещение как фактор экономического развития региона или отдельных предприятий (в том числе на основе индустриализации, внедрения технологичных производств).

5. Импортозамещение как двуединый процесс развития внутреннего и внешнего рынка на основе укрепления позиций отечественной продукции на них.

Трактовка понятия «импортозамещение» в трудах современных ученых Interpretation of the concept of «import substitution» in the works of modern scientists

\begin{tabular}{|c|c|c|}
\hline $\begin{array}{l}\text { № } \\
\text { П/ח }\end{array}$ & Автор & Определение \\
\hline 1 & $\begin{array}{l}\text { Х. Ченери и } \\
\text { Н. Картер } \\
\text { [Ченери Х., } \\
\text { 1972] }\end{array}$ & $\begin{array}{l}\text { Стимул развития национальной экономики, такой способ включения } \\
\text { государства в мировое хозяйство, при котором рост экономики обусловлен } \\
\text { развитием внутреннего рынка промышленных товаров }\end{array}$ \\
\hline 2 & $\begin{array}{l}\text { Е.Г. Анимица, } \\
\text { П.Е. Анимица, } \\
\text { А.А. Глумов } \\
\text { [Анимица Е.Г., } \\
\text { 2015] }\end{array}$ & $\begin{array}{l}\text { Сокращение ввоза из-за рубежа в страну } \\
\text { дальнейшим его производством собственг }\end{array}$ \\
\hline 3 & $\begin{array}{l}\text { A.H. } 1 \\
\text { [Maта } \\
2003]\end{array}$ & 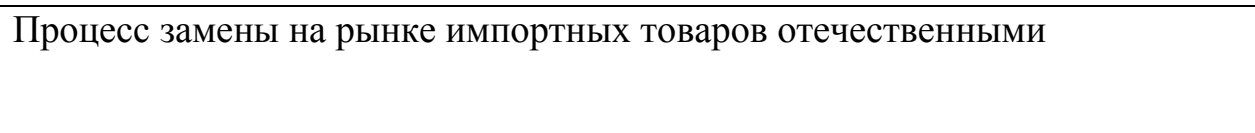 \\
\hline 4 & щева & $\begin{array}{l}\text { Сокращение импорта определенной группы товаров с одновременным } \\
\text { развитием внутриориентированного производства } \\
\begin{array}{l}\text { аналогичных товаров } \\
\text { таких }\end{array}\end{array}$ \\
\hline 5 & $\begin{array}{l}\text { Е. Лукьянчук } \\
\text { [Лукьянчук, Е., } \\
\text { 2011.] }\end{array}$ & $\begin{array}{l}\text { Ограничение поставки в страну определенных импортных товаров, } \\
\text { сопровождаемое замещением их на внутреннем рынке товарами } \\
\text { собственного производства, соответствующими требованиям потребителя }\end{array}$ \\
\hline 6 & $\begin{array}{l}\text { О.П. Зайцева } \\
\text { [Зайцева О.П., } \\
\text { 2018.] }\end{array}$ & $\begin{array}{l}\text { Важный экономический инструмент реализации стратегии развития } \\
\text { государства, характеризующийся модернизацией ряда отраслей } \\
\text { национальной экономики, с учетом их конкурентных и географических } \\
\text { характеристик. }\end{array}$ \\
\hline 7 & $\begin{array}{l}\text { В.А. Семыкин, } \\
\text { В.В. Сафронов, } \\
\text { В.П. Терехов. } \\
\text { [Семыкин В.А., } \\
\text { 2014] }\end{array}$ & $\begin{array}{l}\text { Повышающий независимость экономики от внешних рисков процесс } \\
\text { оптимизации структуры народного хозяйства страны, обеспечиваемый } \\
\text { созданием дополнительных замещающих импорт производств и видов } \\
\text { экономической деятельности. }\end{array}$ \\
\hline 8 & $\begin{array}{l}\text { П.А. Ершов } \\
\text { [Ершов П.А., } \\
\text { 2017] }\end{array}$ & $\begin{array}{l}\text { Сценарий развития национальной экономики, результатом которого } \\
\text { является способность выпускать внутри страны товары с более значимыми } \\
\text { конкурентными преимуществами, чем ранее импортируемые аналоги }\end{array}$ \\
\hline
\end{tabular}


Обобщая приведенные тезисы, отметим, что, на наш взгляд, политика импортозамещения - это ряд принятых государством взаимосвязанных мер, направленных на поддержку приоритетных секторов экономики с целью повышения конкурентоспособности выпускаемого в них продукта, стабилизации развития внутреннего рынка и экспортной деятельности и, в конечном счете, обеспечения экономической безопасности страны.

Как отмечают Зус В.А. и Лягин Л.М., правильный вектор реализации политики импортозамещения должен соответствовать приоритетным направлениям национальной экономической стратегии [Zus, 2018]. Следует отметить, что в России статистика показателей, характеризующих импортозамещение, ведется по следующим направлениям:

- производство основных видов импортозамещающих продуктов питания;

- сельское хозяйство;

- торговля, включая товарную структуру импорта по группам продовольственных и сельскохозяйственных товаров, минеральных продуктов, продукции химической, кожевенной, деревообрабатывающей, текстильной, металлургической промышленности, машин, оборудования и транспортных средств.

Все экономические направления политики импортозамещения взаимосвязаны между собой. Так, например, для производства импортозаменяющих продуктов питания необходимо сырье, которое также должно производиться в условиях экономической безопасности. Считается, что в условиях импортозамещения продукт, поступающий на прилавок магазина, производится на $90 \%$ из отечественного сырья и на отечественном оборудовании [Poulsen, 2015]. Немаловажным является развитие сектора машиностроения, обеспечивающего предприятия пищевой промышленности оборудованием, обеспечивающим возможность выпуска конкурентоспособной продукции, не уступающей по набору потребительских свойств зарубежным аналогам. В рамках РПИ важным и необходимым является развитие каждого вида экономической деятельности, определенного правительством для участия в программе импортозамещения.

Анализ импорта РФ (табл. 2) демонстрирует относительную стабильность его товарной структуры и количественный рост объемов импортируемой продукции по средне- и высокотехнологичным направлениям производств.

Таблица 2

Table 2

Товарная структура импорта РФ

Commodity structure of Russian imports

\begin{tabular}{|l|c|c|c|c|}
\hline \multirow{2}{*}{ Наименование } & \multicolumn{2}{c|}{2015} & \multicolumn{2}{c|}{2019} \\
\cline { 2 - 5 } & $\begin{array}{c}\text { млн долл. } \\
\text { США }\end{array}$ & $\%$ & $\begin{array}{c}\text { млн долл. } \\
\text { США }\end{array}$ & $\%$ \\
\hline Импорт - всего & 162436 & 100,0 & 218779 & 100,0 \\
\hline $\begin{array}{l}\text { Продовольственные товары и сельскохозяйственное } \\
\text { сырье для их производства }\end{array}$ & 21704 & 13,4 & 26221 & 12,0 \\
\hline Минеральные продукты & 2844 & 1,8 & 4473 & 2,0 \\
\hline Продукция химической промышленности, каучук & 30355 & 18,7 & 43400 & 19,8 \\
\hline Кожевенное сырье, пушнина и изделия из них & 718 & 0,4 & 1147 & 0,5 \\
\hline Древесина и целлюлозно-бумажные изделия & 3050 & 1,9 & 3316 & 1,5 \\
\hline Текстиль, текстильные изделия и обувь & 9831 & 6,1 & 13579 & 6,2 \\
\hline Металлы, драгоценные камни и изделия из них & 10543 & 6,5 & 16982 & 7,8 \\
\hline Машины, оборудование и транспортные средства & 77087 & 47,5 & 101027 & 46,2 \\
\hline Прочие товары & 6299 & 3,9 & 8632 & 3,9 \\
\hline
\end{tabular}

Источник: Данные Росстата (https://rosstat.gov.ru/folder/11188/) 
Как мы видим, из товарной структуры импорта Российской Федерации объем импорта не значительно уменьшился, а в некоторых случаях даже и увеличился, хотя РПИ должна приводить к сокращению импорта продукции с целью производства отечественного аналога товара с последующим ориентиром его на экспорт с выходом на новый мировой рынок.

Данные тенденции не согласуются с идеями увеличения технологичности ВВП в рамках вектора формирования и реализации инновационной экономики. Вместе с тем по группе товаров, обеспечивающих продовольственную безопасность страны (а они согласно пирамиде А. Маслоу удовлетворяют базовые потребности населения), отмечается положительный структурный сдвиг, выражаемый, соответственно, и в сокращении доли импорта товаров в их товарных ресурсах (рис.1).

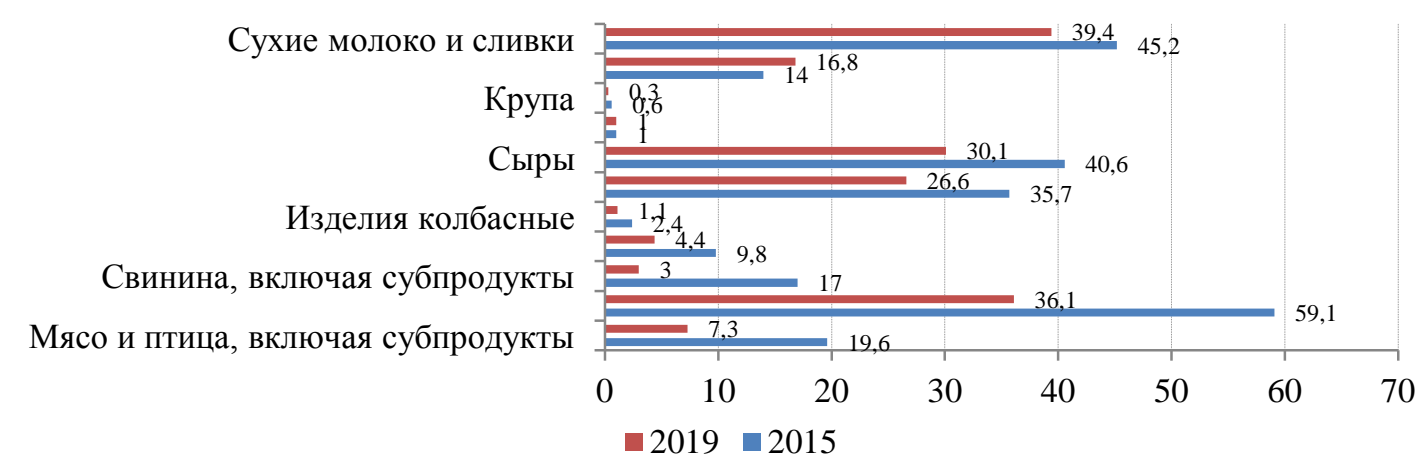

Рис. 1. Доля импорта отдельных товаров в их товарных ресурсах до и после РПИ в РФ, данные приведены за 2015 и 2019 гг.

Fig 1. The share of imports of individual goods in their commodity resources before and after the implementation of the import substitution policy of Russian, data is provided for 2015 and 2019.

(Источник: Данные Росстата (https://rosstat.gov.ru/folder/11188/)))

Таким образом, проведя анализ импорта РФ (см. табл. 2) и анализ отдельных товаров (см. рис. 1), можно сделать вывод о снижении объема импорта в РФ, особенно в продовольственном секторе.

Поскольку в продовольственном секторе отмечается наиболее существенный эффект реализации политики импортозамещения, далее целесообразно провести более глубокий анализ касающихся его изменений.

Измерение средних темпов роста внутреннего производства по каждой группе продуктов питания до и после РПИ (табл. 3) позволяет сделать вывод об интенсификации производства и продаж предприятий продовольственного сектора, что совместно с выявленным ранее фактом о снижении доли импорта в товарных ресурсах продовольствия свидетельствует об эффективности деятельности предприятий сектора и в части удовлетворения освободившихся рыночных сегментов.

Снижение темпов роста объемов внутреннего производства продуктов питания наблюдается в малой доле подотраслей. В случае выпуска колбасных изделий действует фактор потребительских предпочтений, переориентирующий российских потребителей на приобретение натурального мяса. В случае некоторых рыбных продуктов и сыра действует фактор существования импорта из дружественных стран.

Более глубокое изучение рыночных процессов предлагается осуществить на примере мясной промышленности, поскольку в ней наблюдается однозначно положительная динамика эффекта импортозамещения. Среди наиболее устойчивых трендов импортозамещения в данном секторе, которые можно транслировать на другие промышленные экономические системы, можно отметить следующие:

1.Изменение структуры спроса, обусловленное трансформацией демонстрируемых потребительских предпочтений, выражаемых, в частности, в видовой структуре приобретаемого продукта (рис. 2, рис. 3). 
Оценка темпов роста внутреннего производства продуктов питания до и после начала реализации политики импортозамещения (РПИ) в РФ

Assessment of the growth rate of domestic food production before and after the implementation of the import substitution policy of Russian

\begin{tabular}{|c|c|c|c|c|c|c|c|c|c|c|c|c|}
\hline $\begin{array}{l}\text { № } \\
\text { ПI/II }\end{array}$ & $\begin{array}{c}\text { Виды } \\
\text { продуктов } \\
\text { питания, } \\
\text { тыс. т }\end{array}$ & 올 & $\overline{\text { จे }}$ & 고ำ & $\stackrel{m}{\stackrel{2}{\sim}}$ & $\stackrel{\nabla}{\vec{\nu}}$ & 농 & $\stackrel{0}{\stackrel{2}{*}}$ & 공 & $\stackrel{\infty}{\stackrel{\sim}{\circ}}$ & 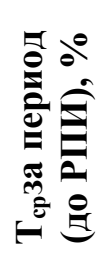 & 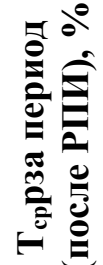 \\
\hline 1 & 2 & 3 & 4 & 5 & 6 & 7 & 8 & 9 & 10 & 11 & 12 & 13 \\
\hline 1 & $\begin{array}{l}\text { Мясо крупного } \\
\text { рогатого скота } \\
\text { парное, } \\
\text { остывшее, } \\
\text { охлажденное }\end{array}$ & 219 & 190 & 177 & 198 & 185 & 203 & 194 & 205 & 227 & 96,2 & 105,4 \\
\hline 2 & $\begin{array}{l}\text { Мясо крупного } \\
\text { рогатого скота } \\
\text { подмороженное, } \\
\text { замороженное, } \\
\text { глубокой } \\
\text { заморозки и } \\
\text { размороженное }\end{array}$ & 43 & 38 & 36 & 41 & 43 & 51 & 49 & 56 & 70 & 100,6 & 113,6 \\
\hline 3 & $\begin{array}{l}\text { Свинина } \\
\text { парная, } \\
\text { остывшая, } \\
\text { охлажденная }\end{array}$ & 754 & 815 & 941 & 1231 & 1438 & 1655 & 1947 & 2171 & 2414 & 117,8 & 113,9 \\
\hline 4 & $\begin{array}{l}\text { Свинина } \\
\text { подмороженная, } \\
\text { замороженная, } \\
\text { глубокой } \\
\text { заморозки и } \\
\text { размороженная } \\
\end{array}$ & 57 & 61 & 58 & 67 & 97 & 108 & 94 & 233 & 253 & 115,3 & 138,4 \\
\hline 5 & $\begin{array}{l}\text { Мясо и } \\
\text { субпродукты } \\
\text { пищевые } \\
\text { домашней } \\
\text { птицы } \\
\end{array}$ & 2773 & 3027 & 3404 & 3610 & 3978 & 4339 & 4464 & 4839 & 4877 & 109,5 & 105,3 \\
\hline 6 & $\begin{array}{l}\text { Изделия } \\
\text { колбасные }\end{array}$ & 2438 & 2486 & 2533 & 2501 & 2475 & 2445 & 2436 & 2259 & 2282 & 100,4 & 98,0 \\
\hline 7 & $\begin{array}{l}\text { Рыба живая, } \\
\text { свежая или } \\
\text { охлажденная }\end{array}$ & 1151 & 1395 & 1398 & 1460 & 1167 & 1175 & 1341 & 111 & 154 & 101,5 & 90,3 \\
\hline 8 & $\begin{array}{l}\text { Ракообразные } \\
\text { немороженые; } \\
\text { устрицы; } \\
\text { водные } \\
\text { беспозвоночные } \\
\text { прочие, живые, } \\
\text { свежие или } \\
\text { охлажденные }\end{array}$ & 39 & 42 & 44 & 52 & 55 & 67 & 63 & 45 & 52 & 108,8 & 100,7 \\
\hline
\end{tabular}


Окончание табл. 3

\begin{tabular}{|c|c|c|c|c|c|c|c|c|c|c|c|c|}
\hline 1 & 2 & 3 & 4 & 5 & 6 & 7 & 8 & 9 & 10 & 11 & 12 & 13 \\
\hline 9 & $\begin{array}{l}\text { Филе рыбное, } \\
\text { мясо рыбы } \\
\text { прочее, печень, } \\
\text { икра и молоки } \\
\text { рыбы свежие } \\
\text { или } \\
\text { охлажденные }\end{array}$ & 16 & 16 & 16 & 18 & 21 & 18 & 20 & 17 & 17 & 106,4 & 95,8 \\
\hline 10 & $\begin{array}{l}\text { Рыба (кроме } \\
\text { сельди) } \\
\text { мороженая, } \\
\text { печень, икра и } \\
\text { молоки рыбы } \\
\text { мороженые }\end{array}$ & 2292 & 2355 & 2337 & 2433 & 2347 & 2501 & 2606 & 3057 & 3057 & 100,6 & 107,0 \\
\hline 11 & $\begin{array}{l}\text { Филе рыбное } \\
\text { мороженое }\end{array}$ & 71 & 86 & 94 & 108 & 109 & 123 & 141 & 146 & 155 & 111,5 & 109,1 \\
\hline 14 & $\begin{array}{l}\text { Рыба (кроме } \\
\text { сельди) } \\
\text { копченая }\end{array}$ & 57 & 59 & 61 & 63 & 61 & 57 & 53 & 58 & 65 & 101,8 & 102,0 \\
\hline 15 & $\begin{array}{l}\text { Плодоовощная } \\
\text { продукция } \\
\text { замороженная }\end{array}$ & 24 & 38 & 40 & 45 & 45 & 55 & 71 & 62 & 55 & 118,8 & 106,7 \\
\hline 16 & $\begin{array}{l}\text { Фрукты, ягоды } \\
\text { и орехи } \\
\text { сушеные }\end{array}$ & 3 & 3 & 4 & 10 & 12 & 12 & 11 & 15 & 16 & 145,5 & 110,0 \\
\hline 17 & $\begin{array}{l}\text { Молоко жидкое } \\
\text { обработанное }\end{array}$ & 4943 & 4926 & 5267 & 5385 & 5349 & 5448 & 5569 & 5390 & 5466 & 102,0 & 100,6 \\
\hline 18 & Сливки & 80 & 83 & 95 & 103 & 114 & 120 & 125 & 133 & 150 & 109,3 & 107,0 \\
\hline 19 & Творог & 376 & 382 & 396 & 371 & 387 & 415 & 410 & 486 & 501 & 100,8 & 106,9 \\
\hline 20 & $\begin{array}{l}\text { Масло } \\
\text { сливочное }\end{array}$ & 210 & 217 & 214 & 224 & 250 & 256 & 250 & 270 & 267 & 104,6 & 101,7 \\
\hline 21 & $\begin{array}{l}\text { Сыры и } \\
\text { продукты } \\
\text { сырные } \\
\end{array}$ & 437 & 432 & 450 & 434 & 499 & 588 & 605 & 464 & 467 & 103,6 & 99,5 \\
\hline 22 & $\begin{array}{l}\text { Продукты } \\
\text { молочные } \\
\text { сгущенные, } \\
\text { млн усл. банок }\end{array}$ & 883 & 854 & 872 & 860 & 832 & 827 & 854 & 837 & 806 & 98,6 & 99,2 \\
\hline 23 & $\begin{array}{l}\text { Продукты } \\
\text { кисломолочные, } \\
\text { кроме сметаны } \\
\text { и творога }\end{array}$ & 2388 & 2318 & 2429 & 2520 & 2519 & 2444 & 2491 & 2896 & 2820 & 101,4 & 103,1 \\
\hline
\end{tabular}

$\mathrm{T}_{\mathrm{cp}}$ - средний темп роста.

(Источник: Данные Росстата (https://rosstat.gov.ru/folder/11188/))

Продовольственное эмбарго на ввоз импортной свинины создало возможности для роста внутреннего производства аналогичной продукции. Но снижение доли потребляемой свинины в структуре потребления мяса обусловлено недостаточностью предложения либо в части количества продукта и его цены, либо в части качественных параметров товара. В этом смысле существуют маркетинговые возможности открытия новых рыночных окон, а также встает вопрос о целесообразности проведения рекламных кампаний, уточняющих конкурентные преимущества производителей. 
2. Насыщение рынков. Текущая емкость рынка мяса и мясопродуктов оценивается по объему производства, импорта и экспорта (рис. 3).

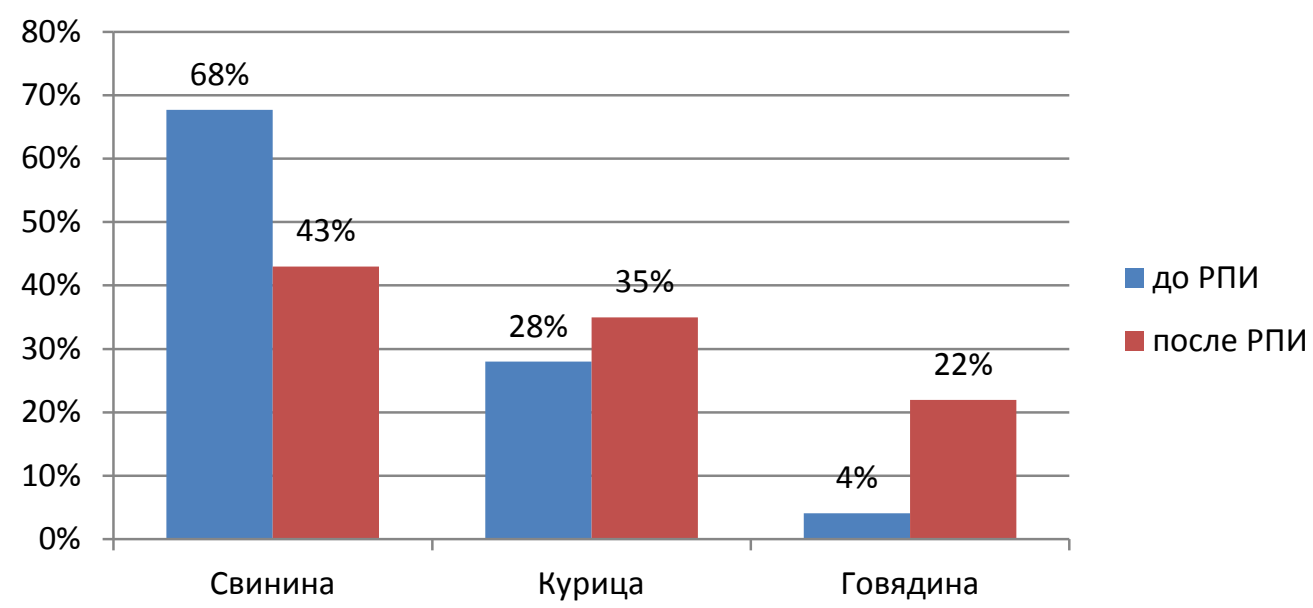

Рис. 2. Структура рынка мяса РФ до и после введения РПИ, данные приведены за 2015 и 2019 гг.

Fig 2. The structure of the meat market of Russian, data is provided for 2015 and 2019.

(Источник: Данные Росстата (https://rosstat.gov.ru/folder/11188/))

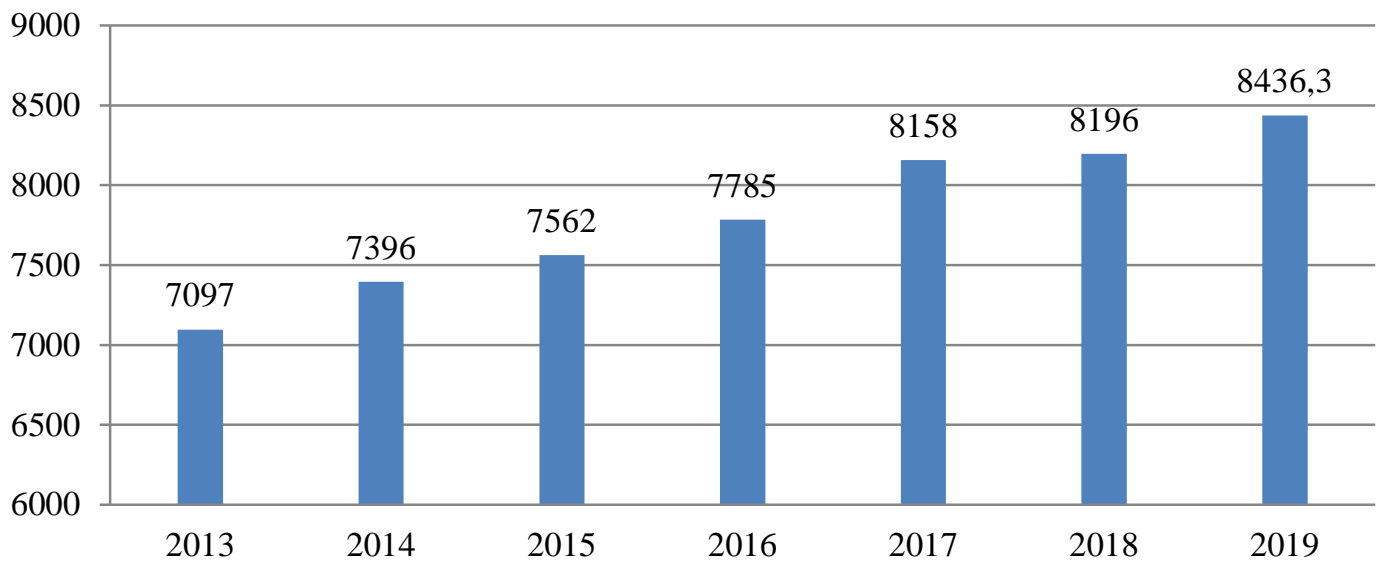

Рис. 3. Динамика емкости рынка мяса в РФ, тыс. т

Fig 3. The Dynamics of market capacity of Russian of meat $t$ (Источник: Данные Росстата (https://rosstat.gov.ru/folder/11188/))

В России в 2018году объем потребления мяса вырос на 0,4 \%, а в 2019 году - на 3 \%, что ниже существовавших до 2016 года темпов прироста [Zus, 2018]. Торможение темпов развития рынка свидетельствует о его насыщении и необходимости использования приемов маркетинговой дифференциации и выявлении возможностей увеличения спроса, в том числе с учетом экспорта.

3. Увеличение концентрации игроков на рынке. Для полной оценки трансформации рыночной среды в результате РПИ представим конкурентную структуру рынка мяса до и после РПИ.

Расчет индекса Херфиндаля - Хиршмана определяет рост концентрации, не приводящий, однако, к коренному изменению структуры рынка (значение 231 до РПИ против 301 после РПИ). Данная тенденция свидетельствует о том, что возможности по производству товаров для временно неудовлетворенного спроса были использованы средним и крупным бизнесом, а существующие в секторе барьеры трудно преодолевать малым предприятиям. 
Ресурсы крупных компаний достаточны для повышения конкурентоспособности продукции, что является необходимой мерой для развития спроса.

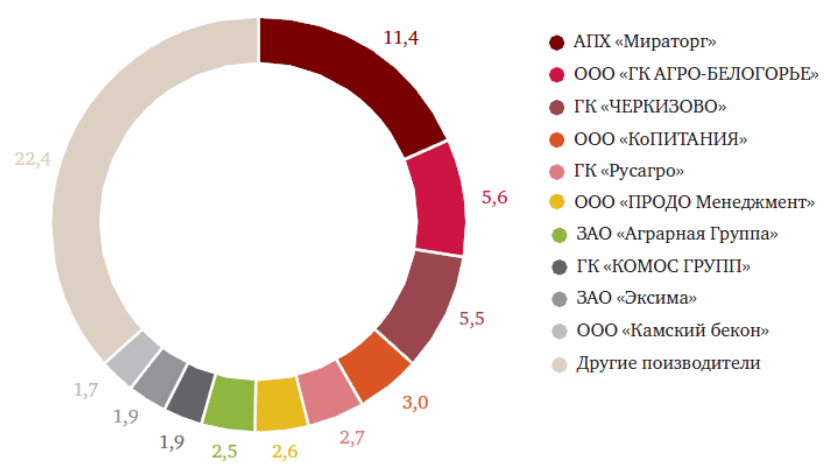

Рис. 4. Доли рынка российских компаний на рынке мяса и мясных продуктов после РПИ, данные приведены за 2019 г.

Fig. 4. Market shares of Russian companies in the meat and meat products market after the IISP, data is provided for 2019

(Источник: Данные журнала АгроИнвестор (https://www.agroinvestor.ru/markets/))

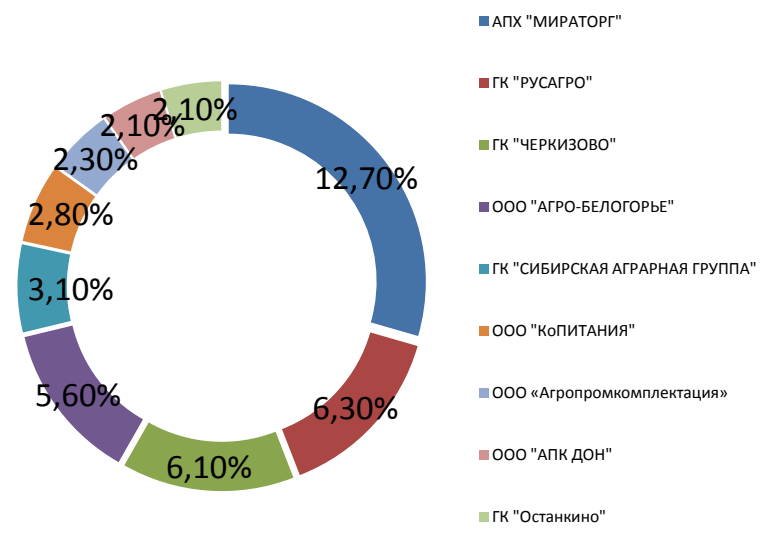

Рис. 5. Доли рынка российских компаний на рынке мяса и мясных продуктов до РПИ, данные приведены за 2015 г.

Fig 5. Market shares of Russian companies in the meat and meat products market before the IISP, data is provided for 2015

(Источник: Данные журнала АгроИнвестор (https://www.agroinvestor.ru/markets/))

\section{Заключение}

Проведя анализ эффектов реализации политики импортозамещения в контексте трансформации рыночной среды, можем сделать следующие выводы:

1. Реализация политики импортозамещения имеет несколько направлений, которые в случае неудачных стечений обстоятельств могут привести к спаду национальной экономики и безопасности. Сам процесс РПИ требует значительных финансовых вложений как со стороны государства, так и со стороны самого предприятия, что может оказать негативное влияние на его конкурентоспособность. Положительный результат РПИ может дать высокий экономический эффект, выражающийся не только в возможности российских производителей укрепить свои позиции на внутреннем рынке, но и в расширении сфер влияния на глобальных рынках. Иными словами, у игроков рынка появляется две альтернативные рыночные 
стратегии: краткосрочный успех на внутреннем рынке в результате появления значительного объема неудовлетворенного спроса и долгосрочный успех с возможностью перспективного успешного выхода на экспортные рынки на основе формирования устойчивой конкурентоспособности продукции. На наш взгляд, существование нейтральных и негативных количественных эффектов импортозамещения вызвано эксплуатацией промышленными предприятиями первой стратегии.

2. Текущие позитивные эффекты импортозамещения в российской экономике проявляются, главным образом, в обеспечении продовольственной безопасности. Существенного снижения доли импорта в продукции машиностроения и других технологичных видах экономической деятельности не наблюдается. Анализ российского рынка по производству основных продуктов питания показал, что темпы роста производства в целом выросли после введения РПИ, что, однако, не является единственным проявлением протекционистской политики.

3. Более глубокое изучение эффектов импортозамещения на примере рынка мяса (как сегмента продовольственного рынка, демонстрирующего наибольший отклик на нейтрализацию санкционной политики) свидетельствует о существовании тренда на изменение структуры спроса (данный тренд продолжается и в период пандемии коронавируса, что обусловлено снижением покупательной способности населения и изменением форматов продаж), на насыщение рынка и улучшение позиций крупных и средних предприятий. Вместе с тем, развитие национальной экономики связывается с укреплением статуса малого бизнеса. Однако, как показал анализ, условия наибольшего благоприятствования для развития в условиях реализации политики импортозамещения не предоставляют больше шансов для стабилизации и роста малого предпринимательства в промышленности и требуют введения дополнительных мер его поддержки.

\section{Список литературы}

1. Азоев Г.Л., Поршнев А.Г. и др. 2000. Маркетинг. Словарь. М.: Экономика, 362.

2. Анимица Е.Г., Анимица П.Е., Глумов А.А. 2015. Импортозамещение в промышленном производстве региона: концептуально-теоретические и прикладные аспекты. Экономика региона, 3: 163-164.

3. Ван дер Вее Г. История мировой экономики. 1945-1990., 1994.: пер. с фр. М.: Наука, 413 с.

4. Волкодавова Е.В. 2009. Реализация стратегии импортозамещения продукции на российских промышленных предприятиях. Экономические науки, 12: 281-286.

5. Гулин К.А., Мазилов Е.А., Ермолов А.П. 2015. Импортозамещение как инструмент активизации социально-экономического развития территорий. Проблемы развития территории, 3 (77): 7-25.

6. Ершов П.А. 2017. Импортозамещение и политика импортозамещения: теоретический подход к определению понятий. Вестник Института экономики Российской академии наук, 2: 147-157.

7. Зайцев Д.Н. 2002. Организация производства импортозамещающей продукции как направление экономического развития региона: дисс. ... канд. экон. наук. Оренбург, 175.

8. Зайцева О.П. 2018. Совершенствование государственной поддержки сельского хозяйства в условиях импортозамещения, дис. ... к-та экон. наук: 08.00.05 Зайцева Ольга Петровна. Омск, 162.

9. Исмагилова Л.Р. 2004. Развитие экспортоориентированных и импортозамещающих производств как фактор интеграции региона в систему мирохозяйственных связей: дисс. ... канд. экон. наук. Казань, 202.

10.Лукьянчук Е. 2011. Импортозамещение: зарубежный опыт. Еженедельник АПТЕКА, 786 (15): 19-20.

11.Макаров А.Н. 2011. Импортозамещение как инструмент индустриализации экономики региона. Инновационный аспект. На примере Нижегородской области. Инновации, 5: 90-93.

12.Матанцев А.Н. 2003. 600 способов продвижения торговой марки. М.: Дело и сервис, 352.

13.Назарчук Е.Н. 2007. Теоретические и методические основы эффективного импортозамещения на российских промышленных предприятиях: дисс. ... канд. экон. наук. Самара, 137.

14.Румянцева Е.Г. 2005. Новая экономическая энциклопедия. М.: Инфра-М, 724. 
15.Семыкин В.А., Сафронов В.В., Терехов В.П. 2014. Импортозамещение как эффективный инструмент оптимального развития рыночной экономики. Вестник Курской государственной сельскохозяйственной академии, 7: 2-7.

16. Ченери Х., Картер Н. 1972. Внутренние и внешние аспекты планов и процесса экономического развития. Конференция по долгосрочному планированию и прогнозированию. Москва, 5: 77-110.

17.Fanzo J. 2015. Ethical Issues for Human Nutrition in the Context of Global Food Security and Sustainable Developmen. Global Food Security, (7): 15-23.

18.Poulsen M., McNab P., Clayton M., Neff R.A. 2015. Systematic Review of Urban Agriculture and Food Security Impacts in Low-Income Countries, Food Policy.(55): 131-146.

19. Schetinina E.D., Kochina S.K. 2018. Economic diagnostics in environment of staticized relationship marketing. В сборнике: The European Proceedings of Social \&Behavioural Sciences EpSBS Edited by: Ardashkin I.B., Martyushev N.V., Klyagin S.V., Barkova E.V., Massalimova A.R. \&Syrov V.N.: $1152-1162$.

20.Smyth S., Phillips P., Kerr W. 2015. Food Security and the Evaluation of Risk. GlobalFoodSecurity, 4: 16-23.

21.Zus V.A., Lyagin L.M., Tsitsikiev M.M. 2018 Import substitution in the agrarian sphere of the russian federation. Контентус, 5 (70): 19-27.

\section{References}

1. Azoev G.L., Porshnev A.G. et al. 2000. Marketing. Dictionary. Moscow: Economics, 362.

2. Animitsa E.G., Animitsa P.E., Glumov A.A. 2015. Import substitution in industrial production of the region: conceptual-theoretical and applied aspects. Regional Economics, 3: 163-164.

3. Van der Vee G. History of the world economy. 1945-1990., 1994 .: trans. with fr. Moscow: Nauka, $413 \mathrm{p}$.

4. Volkodavova E.V. 2009. Implementation of the strategy of import substitution of products at Russian industrial enterprises. Economic Sciences, 12: 281-286.

5. Gulin K.A., Mazilov E.A., Ermolov A.P. 2015. Import substitution as a tool for enhancing the socio-economic development of territories. Territory Development Problems, 3 (77): 7-25.

6. Ershov PA 2017. Import substitution and import substitution policy: a theoretical approach to the definition of concepts. Bulletin of the Institute of Economics of the Russian Academy of Sciences, 2: 147-157.

7. Zaitsev D.N. 2002. Organization of production of import-substituting products as a direction of economic development of the region: diss. ... Cand. econom. sciences. Orenburg, 175.

8. Zaitseva O.P. 2018. Improving state support for agriculture in the context of import substitution dis. ... to-that econom. Sciences: 08.00.05 Zaitseva Olga Petrovna. Omsk, 162.

9. Ismagilova L.R. 2004. Development of export-oriented and import-substituting industries as a factor of integration of the region into the system of world economic relations: diss. ... Cand. econom. sciences. Kazan, 202.

10. Lukyanchuk E. 2011. Import substitution: foreign experience. Pharmacy weekly, 786 (15): 19-20.

11. Makarov A.N. 2011. Import substitution as a tool for the industrialization of the region's economy. An innovative aspect. On the example of the Nizhny Novgorod region. Innovation, 5: 90-93.

12. Matantsev A.N. 2003. 600 ways to promote a brand. Moscow: Business and Service, 352.

13. Nazarchuk E.N. 2007. Theoretical and methodological foundations of effective import substitution at Russian industrial enterprises: diss. ... Cand. econom. sciences. Samara,. 137.

14. Rumyantseva E.G. 2005. New economic encyclopedia. M .: Infra-M, 724.

15. Semykin V.A., Safronov V.V. Terekhov V.P. 2014. Import substitution as an effective tool for the optimal development of a market economy. Bulletin of the Kursk State Agricultural Academy, 7: 2-7.

16. Chenery X., Carter N. 1972. Internal and external aspects of plans and the process of economic development. Conference on long-term planning and forecasting. Moscow, 5: 77-110.

17. Fanzo J. 2015. Ethical Issues for Human Nutrition in the Context of Global Food Security and Sustainable Developmen. Global Food Security, (7): 15-23.

18. Poulsen M., McNab P., Clayton M., Neff R. A. 2015. Systematic Review of Urban Agriculture and Food Security Impacts in Low-Income Countries, Food Policy. (55): 131-146.

19. Schetinina E.D., Kochina S.K. 2018. Economic diagnostics in environment of staticized relationship marketing. In the collection: The European Proceedings of Social \& Behavioral Sciences EpSBS 
Edited by: Ardashkin I.B., Martyushev N.V., Klyagin S.V., Barkova E.V., Massalimova A.R. \& SyrovV.N .: $1152-1162$.

20. Smyth S., Phillips R., Kerr W. 2015. Food Security and the Evaluation of Risk. Global Food Security, 4: 16-23.

21. Zus V.A., Lyagin L.M., Tsitsikiev M.M. 2018 Import substitution in the agrarian sphere of the russian federation. Contentus, 5 (70): 19-27.

\section{ИНФОРМАЦИЯ ОБ АВТОРАХ}

\section{Старикова Мария Сергеевна, доктор} экономических наук, доцент, профессор кафедры маркетинга БГТУ им. В.Г. Шухова, Белгород, Россия

Дубровина Татьяна Александровна, старший преподаватель кафедры маркетинга БГТУ им. В.Г. Шухова, Белгород, Россия

\section{INFORMATION ABOUT THE AUTHORS}

Maria S. Starikova, Doctor of Economic Sciences, Associate Professor, Professor of the Department of Marketing BSTU named after V.G. Shukhov, Belgorod, Russia

Tatiana A. Dubrovina, Art. Lecturer at the Department of Marketing BSTU named after V.G. Shukhov, Belgorod, Russia 